\title{
SETTING REALISTIC HEALTH GOALS: ANTECEDENTS AND CONSEQUENCES
}

\author{
Aya Avishai
}

A thesis submitted to the faculty at the University of North Carolina at Chapel Hill in partial fulfillment of the requirements for the degree of Master of Arts in the Department of Psychology and Neuroscience (Social Psychology).

\section{Chapel Hill}

2019

Approved by:

Paschal Sheeran

B. Keith Payne

Keely A. Muscatell 
(C) 2019

Aya Avishai

ALL RIGHTS RESERVED 


\section{ABSTRACT \\ Aya Avishai: SETTING REALISTIC HEALTH GOALS: ANTECEDENTS AND CONSEQUENCES \\ (Under the direction of Paschal Sheeran)}

People often fail to translate their intentions into health behaviors. The present research examined a new potential moderator of intention-behavior relations, namely, how realistic or unrealistic are respective goal intentions. Goal realism was defined as the degree to which intentions are aligned with expectations (i.e., predicted performance). A validation study $(N=81)$ examined our novel goal realism measure. Study $1(N=246)$ tested goal importance, fantasy proneness, and pathways thinking as predictors of realistic goal setting using a cross-sectional questionnaire design. Moderation of the intention-behavior relation was tested in prospective surveys of cervical cancer screening (Study 2, $N=854$ ), physical activity (Study 3, $N=237$ ), and performance of a suite of 15 health behaviors (Study 4, $N=378$ ). The validation study offered preliminary evidence concerning the convergent and predictive validity of the goal realism measure. Study 1 showed that goal importance, fantasy proneness, and pathways thinking interacted to predict how realistic were intentions to perform 11 health behaviors. In Study 2, realistic intentions better predicted women's attendance for cervical cancer screening compared to unrealistic intentions. Study 3 confirmed this finding for a frequently performed behavior (physical activity). In Study 4, multi-level modeling of longitudinal data for 15 health behaviors again revealed a significant goal realism $\times$ intention interaction. Greater realism was associated with improved prediction of behavior by intention. The interaction term remained significant even when past behavior, perceived behavioral control, and other predictors were taken into account. The present findings offer new insights into the factors that 
lead to more realistic intentions, and demonstrate that goal realism influences how effectively intentions are translated into action. 


\section{ACKNOWLEDGEMENTS}

Thank you to my advisor, Dr. Paschal Sheeran, for his mentorship and guidance throughout this and many other projects. I also want to thank Dr. Mark Conner, University of Leeds, for sharing his data and collaborating on this project. 


\section{TABLE OF CONTENTS}

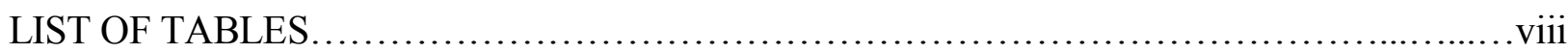

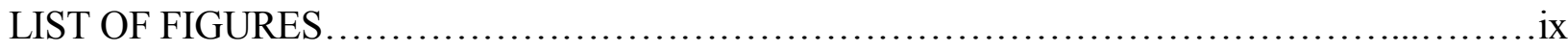

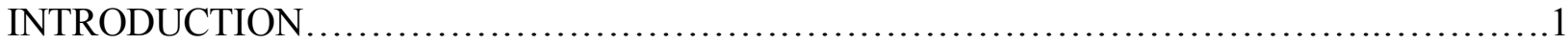

Goal Realism: Operationalization and Implications for Intention Realization..............1

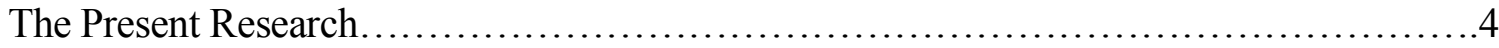

PRELIMINARY VALIDATION OF THE MEASURE OF GOAL REALISM.......................5

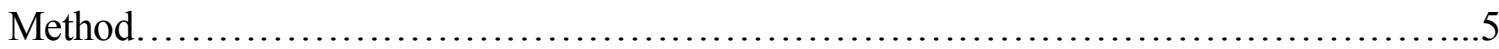

Results and Discussion...............................................................

STUDY 1: ANTECEDENTS OF REALISTIC GOAL SETTING $\ldots \ldots \ldots \ldots \ldots \ldots \ldots \ldots \ldots \ldots . . \ldots$

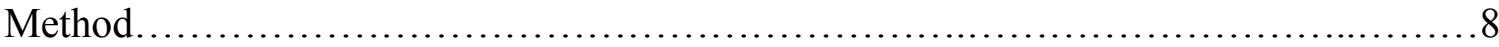

Participants and Procedure...................................................... 8

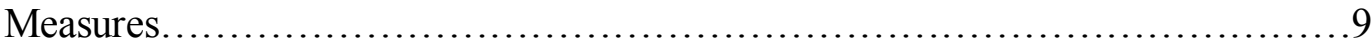

Results and Discussion...............................................................

STUDY 2: GOAL REALISM AND ATTENDING FOR CERVICAL CANCER SCREENING...11

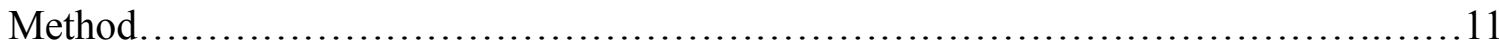

Participants and Procedure....................................................11

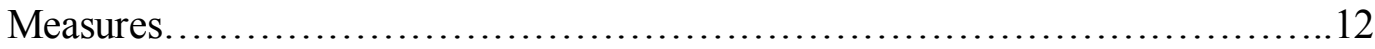

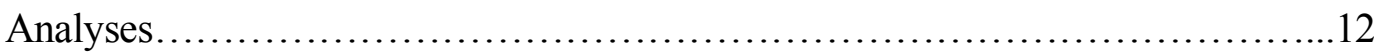

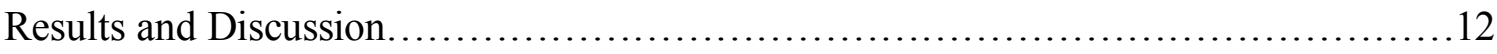

STUDY 3: GOAL REALISM AND PHYSICAL ACTIVITY ..................................14 


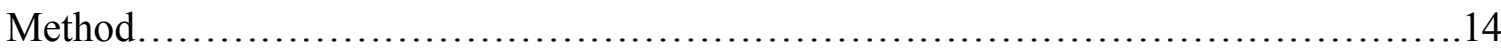

Participants and Procedure...................................................14

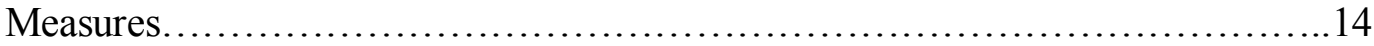

Results and Discussion.......................................................... 15

STUDY 4: GOAL REALISM AND PERFORMANCE OF MULTIPLE

HEALTH BEHAVIORS......................................................................

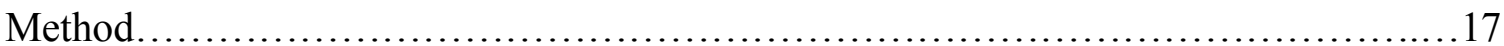

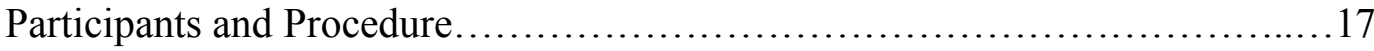

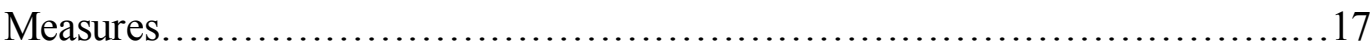

Analyses......................................................................

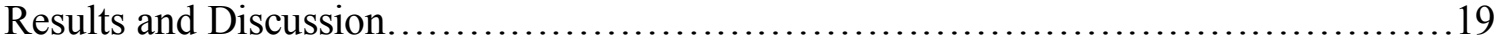

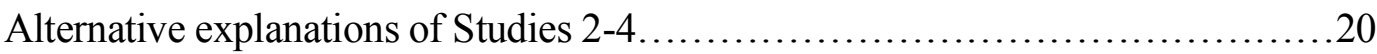

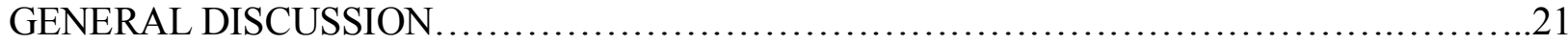

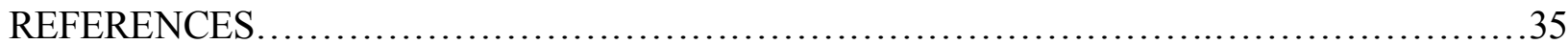




\section{LIST OF TABLES}

Table 1. Descriptives and intercorrelations for variables in Study $1(N=246) \ldots \ldots \ldots \ldots \ldots \ldots \ldots . . \ldots 25$

Table 2. Descriptives and intercorrelations for variables in Study $2(N=854) \ldots \ldots \ldots \ldots \ldots \ldots .26$

Table 3. Logistic regression of behavior on intention, goal realism,

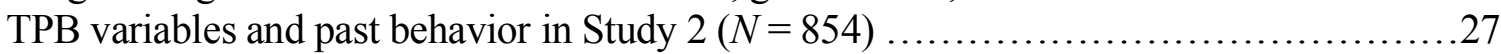

Table 4. Descriptives and intercorrelations for variables in Study $3(N=237) \ldots \ldots \ldots \ldots \ldots \ldots . . .28$

Table 5. Linear regressions of behavior onto intention, goal realism, intention x realism, TPB variables and past behavior in Study $3(N=237) \ldots \ldots \ldots \ldots . .29$

Table 6. Hierarchical multi-level regressions predicting behavior for Study $4(N$ of participants $=378 ; N$ of observations $=4604)$ 


\section{LIST OF FIGURES}

Figure 1. Three-way interaction between fantasy proneness, pathways thinking, and goal importance predicting goal realism in Study $1(N=246) \ldots \ldots \ldots \ldots . . . .31$

Figure 2. Interaction between intention and goal realism predicting

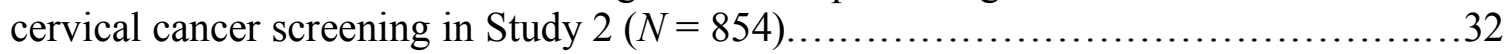

Figure 3. Interaction between intention and goal realism predicting physical activity in Study $3(N=237)$

Figure 4. Interaction between intention and goal realism in predicting 15 health behaviors in Study $4(N$ of participants $=378 ; N$ of observations $=4604) \ldots \ldots .34$ 


\section{INTRODUCTION ${ }^{1}$}

Goals are mental representations of desired outcomes whereas intention formation is the process of setting, and committing oneself to achieving, those goals (Gollwitzer \& Moskowitz, 1996). Although intentions are construed as the most immediate and important predictor of behavior in leading health behavior theories (Fishbein, Triandis, Kanfer, Becker, Middlestadt, \& Eichler, 2001), research indicates that there is a substantial 'gap' between intentions and health behaviors (e.g., McEachan, Conner, Taylor, \& Lawton, 2011; Rhodes \& Bruijn, 2013; Sheeran, 2002). As a result, considerable effort has been devoted to identifying factors that make it more or less likely that intentions will be translated into behavior. For instance, research indicates that properties of intention such as temporal stability are associated with improved prediction of behavior by intention (see Rhodes \& Dickau, 2012, and Sheeran \& Webb, 2016, for reviews). The present research contributes to this work by testing a new moderator of intention-health behavior relations - goal realism. In five studies we explore the validity of our goal realism index (Preliminary Validation Study), predictors of realistic goal setting (Study 1), and test whether setting realistic goals leads to improved translation of intentions into health behaviors (Studies 2-4).

\section{Goal Realism: Operationalization and Implications for Intention Realization}

Imagine the following scenarios: A friend who is obese tells you that he intends to lose 20 pounds in time for his wedding next month; another friend who engages in no leisure-time

This thesis previously appeared as an article in Annals of Behavioral Medicine. The original citation is as follows: Avishai, A., Conner, M., \& Sheeran, P. (2019). Setting realistic health goals: Antecedents and consequences. Annals of Behavioral Medicine. Advance online publication. doi:10.1093/abm/kaz012 
physical activity informs you that she plans to take part in a marathon in 8 weeks time. In both of these scenarios, individuals form healthful intentions; however, the intentions appear 'unrealistic.' That is, it does not seem feasible that these intentions will be translated into action. Although the realism or lack of realism of people's health goals has attracted attention in clinical contexts (e.g., Cunningham, 2014, and Gelinas, Delparte, Hart, Wright, 2013), goal realism has received relatively little theoretical attention in health behavior research (Sheeran \& Webb, 2012). The most influential treatment is Doran's (1981) recommendation that goal setting should be SMART (i.e., Specific, Measurable, Assignable, Realistic, and Time-related).

The difficulty of operationalizing goal realism is likely one reason why this construct has attracted so little research attention. It seems virtually impossible for an observer to determine in advance what is a 'realistic' health goal for any particular person. In the present research, we attempted to overcome this difficulty by exploiting the distinction between intentions ("I intend to do X!" or "I plan to do X!") and expectations ("I predict that I will do X" or "How likely is it that you will do X?"). The intention vs. expectation distinction rests on the idea that a person may hold a strong intention and sincerely mean to perform a behavior, but also recognize the goal is very difficult to attain and so hold low expectations for its attainment. Measures of expectations take greater account of competing alternative behaviors and obstacles to goal achievement than intention measures (Sheppard, Hartwick, \& Warshaw, 1988) and, consequently, expectations better predict behavior compared to intention (e.g., Armitage, Norman, Alganem, \& Conner, 2015; see Sheppard et al., 1988, for a meta-analysis). Thus, goal realism is operationalized here as the extent to which intentions and expectations about health behaviors are aligned. Realistic goals mean that people's intentions and expectations are consistent whereas intentions and expectations do not marry up for unrealistic goals. 
Construing goal realism in terms of the consistency between intentions and expectations has the advantages that (a) how realistic is the respective intention is computed within-persons (in terms of the alignment of participants' own intentions and expectations) and does not require an omniscient observer, and (b) goal realism can be assessed prior to performance of the behavior (using measures of intentions and expectations obtained beforehand). But how should the consistency or alignment of intentions and expectations be characterized quantitatively? One strategy might be to use difference scores (intention minus expectation). Assume for a moment that an intention scale ranges from 1 (definitely do not intend to act) to 7 (definitely intend to act) and the expectation scale also ranges from 1 (definitely do not expect to act) to 7 (definitely expect to act). Now, imagine that one participant rates their intention to perform a health behavior as "2" and their expectation as " 1 " on these scales. Another participant indicates that their intention is " 7 " and their expectation is "6." Using a difference score approach, both participants receive a goal realism score of "1." However, the meaning of these two " 1 " scores is very different as the first participant hardly intends to act whereas the second participant holds a very strong intention. Difference scores are problematic because these indices fail to discriminate potentially significant differences among the input scores used in their computation (see Griffin, Murray, \& Gonzalez, 1999, for discussion of the problems with using difference scores to assess complex psychological phenomena).

We followed Griffin's lead in overcoming this problem by adopting his formula for ambivalence (Thompson, Zanna, \& Griffin, 1995), and adapting it to the issue of intentions versus expectations as follows: Goal realism $=\frac{\text { Intentions }+ \text { Expectations }}{2}-\mid$ Intentions - Expectations $\mid$ The Griffin ambivalence formula, which has been shown to have superior properties compared to other ambivalence indices (Breckler, 1994), has two key advantages. First, the formula takes into account not only the similarity of input ratings, but also the extremity of those ratings. Second, the 
formula privileges more extreme or high scores, allowing us to focus on individuals who strongly intend to perform a particular health behavior. (People who strongly intend but fail to act are mainly responsible for the intention-behavior gap [Sheeran, 2002].) Using this formula, a participant with a score of "7" on intentions and "6" on expectations would receive a goal realism score of 5.5 whereas a participant who scored " 2 " on intentions and " 1 " on expectations would receive 0.5 for goal realism.

Is it safe to assume that greater goal realism is associated with improved translation of intentions into action? On the one hand, research on counteractive optimism suggests that holding optimistic goals actually increases task persistence and performance (Zhang \& Fishbach, 2010). On the other hand, two other lines of research suggest that goal realism should strengthen intention-behavior relations. First, research on the planning fallacy (Buehler, Griffin, \& Ross, 1994) offers a clear-cut example of negative impact of unrealistic goals on task performance as the fallacy demonstrates that people dramatically underestimate task completion times - likely because they fail to take account of relevant past experiences. Second, fantasy realization theory shows that fantasizing about an action has negative consequences for motivation and performance (review, Oettingen, 2012). Fantasizing does not involve thinking about the effort it will take to achieve a goal, so when people fantasize their intentions can become unrealistic (inflated) and less likely to be translated into behavior.

\section{The Present Research}

In one study, we test the validity of our measure of goal realism. In four further studies we examine (a) the antecedents of goal realism (Study 1), and (b) the consequences of goal realism for intention-behavior relations (Study 2-4). 


\section{PRELIMINARY VALIDATION OF THE MEASURE OF GOAL REALISM}

We conducted a validation study in response to feedback to our initial submission, and after Studies 1-4 had been conducted. The study had two aims, namely, to demonstrate that our goal realism measure (a) is associated with an independent, self-report index of how realistic are set goals and (b) offers superior moderation of the predictive validity of intention compared to the self-report measure. Our second hypothesis derives from research on properties of attitudes and intentions (Bassili, 1996) indicating that operative measures (i.e., indirect measures that are inferred from participants' responses) are more valid than direct self-reports (i.e., metajudgments). Thus, we predicted that our operative measure of goal realism - but not the selfreport measure - would moderate the relationship between intentions and anticipated disappointment (Oettingen, Pak, \& Schnetter, 2001). In particular, we predicted that goal realism would weaken the intention-disappointment relation (i.e., failing to enact intentions would lead to less disappointment when participants are realistic about the prospects of intention realization).

\section{Method}

The University of North Carolina at Chapel Hill IRB approved this study. Participants ( $N$ $=81,48.1 \%$ women, $M$-age $=37.94, S D=13.10)$ were recruited via Amazon Mechanical Turk (MTurk) and were rewarded $\$ 0.50$ for a survey concerning their views of 11 health behaviors. Many studies have demonstrated that MTurk offers more diverse and representative samples compared to college students, and results in high quality data (Casler, Bickel, \& Hackett, 2013; Hauser \& Schwarz, 2016). The behaviors were selected on the basis of their importance for good 
health, and comprised 'engaging in at least 150 minutes of moderate physical activity or 75 minutes of vigorous physical activity each week,' 'avoiding snacking between meals,' 'eating a low-fat diet,' 'eating 2-4 servings of fruits each day,' 'eating 3-5 servings of vegetables each day,' 'avoiding drinking sugar-sweetened beverages,' 'flossing at least once a day,' ' avoiding taking illegal drugs,' 'avoiding speeding while driving,' 'using sunscreen on sunny days,' and 'avoiding smoking tobacco.'

Participants first indicated how disappointed they would be if they did not realize their intentions to perform the behaviors (7-point scale, $1=$ not at all disappointed, $7=$ very disappointed, $\alpha=.88$ across the behaviors). Next, participants indicated their intentions to perform each of the 11 health behaviors (7-point scale, $1=$ definitely no, $7=$ definitely yes, $\alpha=$ .80 ) and then rated how realistic were those intentions on a 9-point scale ("How realistic are the intentions you have just reported? That is, how feasible is it that you will do exactly what you said you will do in your intention?”; $1=$ very unrealistic, $9=$ very realistic, $\alpha=.82$ ). Participants then indicated their expectations for each of the health behaviors (7-point scale, $1=$ not at all likely, 7 = extremely likely, $\alpha=.81)$.

To compute our operative measure of goal realism, we applied the Griffin formula to the measure of intentions and the measure of expectations, and computed the average realism across behaviors $(\alpha=.78)$.

\section{Results and Discussion}

Findings showed that our operative measure of goal realism was significantly and strongly correlated with self-reported realism $(r=.77, p<.001)$.

In a moderated regression analysis of anticipated disappointment on the measures of intention and operative goal realism, the intention $\times$ goal realism interaction proved significant $(\beta$ 
$=-.29, p<.01)$. Simple slopes analyses indicated that more realistic intentions $(M+1 S D)$ led to less disappointment $(\mathrm{B}=.74, S E=.36, p=.04)$ compared to less realistic intentions $(\mathrm{B}=1.40$, $S E=.34, p<.001)$. Self-reported realism, on the other hand, did not moderate the intentiondisappointment relation $(\beta=-.18, p=.12)$.

These findings offer preliminary evidence that computing goal realism using the Griffin formula is valid. Our index of goal realism was correlated with self-reported realism and better moderated the relationship between intention and anticipated disappointment compared to selfreported goal realism. 


\section{STUDY 1: ANTECEDENTS OF REALISTIC GOAL SETTING}

In Study 1, we tested three predictors of goal realism: goal importance, fantasy proneness, and pathways thinking. Goal importance refers to the value a person assigns a goal based on his/her experience, and is positively associated with goal commitment and goal striving (Austin \& Vancouver, 1996; Sideridis \& Kaissidis-Rodafinos, 2001). Fantasy proneness is a measure of how often a person daydreams about desirable outcomes (Merckelbach, Horselenberg, \& Muris, 2001). Fantasy realization theory suggests that fantasizing causes people to focus on the desirability of acting rather than its feasibility, and could thus lead to unrealistic intentions. Finally, pathways thinking is the extent to which a person solves problems and thinks through ways to reach goals (Snyder, 2002). Greater pathways thinking should be associated with improved goal realism because intentions are likely to be informed by consideration of how feasible is the goal. We hypothesized that goal importance and pathways thinking would positively predict goal realism whereas fantasizing would negatively predict goal realism.

\section{Method}

Participants and Procedure. The University of North Carolina at Chapel Hill IRB approved this study. We recruited participants online through MTurk and awarded them $\$ 0.50$ for participation. Twenty-five participants (9.2\%) were excluded based on an attention check, leaving 246 participants for analysis. The majority of the sample was white or Caucasian (75.1\%), non-Hispanic (93.1\%), female (55.3\%), and held at least a 2-year college degree (59.8\%). Participants' ages ranged from 18 to 73 years $(M=36.14, S D=11.37)$. The study measures included intention, expectation, and goal importance items regarding 11 health behaviors. 
Additionally, we included a modified version of the Creative Experiences Questionnaire (CEQ; Merckelbach et al., 2001), the Adult Hope Scale (AHS; Snyder et al., 1991), and demographic items. All participants answered the intention items first, followed by goal importance, pathways thinking, and fantasy-proneness in counterbalanced order, then the expectations items, and finally demographics. Data come from a larger project; only items relevant to the present study are described here.

Measures. The behaviors were the same 11 as those used in the validation study. Intentions were measured by asking participants how much they intended to do the behaviors (1 = definitely no, 7 = definitely yes), expectations were assessed by asking participants the likelihood that they would perform the behaviors $(1=$ not at all likely, $7=$ extremely likely $)$, and goal importance was measured by asking people how important were these behaviors $(1=$ not at all important, $7=$ extremely important). Scales were computed by averaging the items across behaviors and proved reliable ( $\alpha \mathrm{s}=.77, .80$, and .84 , respectively). Goal realism $(\alpha=.78)$ was computed using the Griffin formula described previously and used in the Validation Study $(M=$ 4.06, $S D=1.25)$.

Pathways thinking (Snyder, 2002) was measured by 4 items from the AHS (Snyder et al., 1991; e.g., "I can think of many ways to get the things in life that are important to me") and was reliable here $(\alpha=.83)$. Fantasy proneness was measured by the 8 items with the highest itemtotal correlations in the CEQ (Merckelbach et al., 2001) and proved reliable $(\alpha=.78)$.

\section{Results and Discussion}

Descriptives and correlations for Study 1 variables are reported in Table 1. Goal realism was significantly correlated with goal importance $(r=.60, p<.001)$ and pathways thinking $(r=$ $.34, p<.001)$ but not fantasy proneness $(r=.02, p=.72)$. Hierarchical regression of goal realism 
on pathways thinking, goal importance, and fantasy proneness showed that goal importance ( $\beta=$ $.56, p<.001)$ and pathways thinking $(\beta=.22 p<.001)$ both positively predicted realism but fantasy proneness $\operatorname{did} \operatorname{not}(\beta=-.07, p=.16)$. These variables explained $39.7 \%$ of the variance in goal realism, $F(3,242)=54.66, p<.001$.

In the second step of the regression, we added all possible two- and three-way interactions to the equation and observed only a significant three-way goal importance $\times$ fantasy proneness $\times$ pathways thinking interaction $(\beta=-.12, p=.04)$. Plotting the values for goal realism (see Figure 1) indicated that goal realism was greatest when fantasy proneness was low ( $M-$ $1 S D)$ and goal importance and pathways thinking were both high $(M+1 S D)$. Thus, there were synergistic relations among the three predictors examined here in predicting goal realism. 


\section{STUDY 2: GOAL REALISM AND ATTENDING FOR CERVICAL CANCER SCREENING}

Study 2 examined whether goal realism influences the relation between intention to attend, and attendance for, cervical cancer screening.

\section{Method}

Participants and Procedure. Participants were recruited in West Yorkshire, England through a regional screening hub that agreed to send out the study materials along with routine screening letters inviting them to make an appointment for a cervical screening. The National Health Service (NHS) Research Ethics Committee approved this study. Participants were informed that completion of the questionnaire had no bearing on their treatment and provided with contact information in the case that they had questions. A total of 10,000 consecutive eligible invitees were selected between February and May of 2013 and were randomized to one of the following four conditions using a computerized random number generator: 1) control condition, 2) demographic questionnaire condition, 3) Theory of Planned Behavior (TPB) questionnaire condition, 4) TPB questionnaire plus post-it note condition (Conner, Wilding, Sandberg, Wood, Jackson, Godin, Sheeran, unpublished). A total of 344 women were not eligible (e.g., no longer a resident in area, not at known address, deceased, or attended prior to invite), leaving 9,656 women in the sample. Women in the two TPB conditions who completed questionnaires about cervical screening were included in the analyses. The final sample comprised 854 women $(M$-age $=42.4$ years, $S D=10.7)$ and controlling for condition did not affect the results reported here.

Measures. The TPB questionnaire included seven items scored on 7-point Likert scales 
that assessed expectations ("I will attend for a cervical smear in the next few weeks," strongly disagree - strongly agree), intentions ("My intention to attend for a cervical in the next few weeks is..." not at all strong - strong), attitudes ("For me, attending a cervical smear in the next few weeks is..." not worthwhile - worthwhile, harmful - beneficial; $r=.80)$, subjective norm ("People important to me would" disapprove - approve "of me attending for a cervical smear in the next few weeks"), and perceived behavioral control ("I feel I have" no control-complete control "over attending for a cervical smear in the next few weeks,"; "I am confident I can attend for a cervical smear in the next few weeks," strongly disagree-agree; $r=.58$ ). Goal realism was computed in the same manner as the Validation Study and Study 1.

The behavioral outcome was cervical screening attendance over the subsequent 26 weeks (yes/no). Past behavior assessed any previous cervical screening. Both were assessed objectively via medical records.

Analyses. We first examined descriptive data and intercorrelations among the variables. Behavior was then regressed on intentions, goal realism, and the intentions $\times$ goal realism interaction (using mean-centered scores) (step 1), attitudes, subjective norms, and perceived behavioral control (step 2), and past behavior (step 3). Logistic regression was used, as the outcome was dichotomous. Simple slopes analyses were used to explore the relationship between intentions and behavior at different levels of goal realism $(M-1 S D, M+1 S D)$.

\section{Results and Discussion}

Table 2 reports descriptive data and intercorrelations among Study 2 variables. Table 3 shows that intentions were a significant predictor of behavior at step 1 of the logistic regression. At step 2 , intentions and the intentions $\times$ goal realism interaction significantly predicted screening $(\mathrm{B}=$ $.82, p<.001$ and $\mathrm{B}=.10$, respectively, $p \mathrm{~s}<.05)$. The addition of TPB variables and past behavior 
significantly increased the proportion of variance in behavior explained but the intentions $\times$ goal realism interaction remained significant $(\mathrm{B}=.11, p<.01)$. Simple slopes analyses indicated that intentions were a significant predictor of behavior at low $(M-1 S D)$ levels of goal realism, $\mathrm{B}=.65$, $p<.01$, but were a significantly stronger predictor of behavior at high $(M+1 S D)$ levels of realism, $\mathrm{B}=.99, p<.001$ (Figure 2).

These findings indicate that intentions that exhibit greater goal realism better predict behavior compared to intentions with lesser goal realism. The intention $\times$ goal realism interaction remained significant even controlling for TPB variables and past behavior. Study 2 thus offers initial support for our hypotheses that goal realism moderates the intention-behavior relation. 


\section{STUDY 3: GOAL REALISM AND PHYSICAL ACTIVITY}

Study 2 examined an infrequently performed behavior (cervical cancer screening) and used single-item measures of intentions and expectations to compute goal realism. To ensure that these factors did not unduly influence the findings for goal realism, Study 3 used multi-item measures of intentions and expectations and examined a frequently performed behavior (physical activity).

\section{Method}

Participants and Procedure. The University of Leeds IRB approved the research protocol. Participants were a convenience sample of UK university students who completed anonymous paper and pencil or on-line questionnaires at three time-points. Each time-point was separated by two weeks and participants were incentivized to complete and return the questionnaire by a prize draw (two prizes of $£ 50.00$ ). A total of 284 students completed measures at baseline and we were able to match 237 of those students with their responses across all of the time points $(M$-age $=21.3$ years, $S D=3.91$, range $=17$ to 45 years; 139 women, 98 men $)$. All analyses are based on this sample of 237 respondents who were representative of the initial sample in terms of age, gender, and time 1 intentions $(p s>.25)$.

Measures. The questionnaires contained measures of gender, age, intentions, and expectations at time 2 and a measure of exercise behavior at time 3 (all on 7-point scales unless otherwise stated). Additional items at were also measured each time point but are not reported here (see Conner et al., 2016, study 1, for additional information). Intentions were assessed by 2 items ("I intend to exercise vigorously at least 3 times per week for the next two weeks," definitely do not-definitely do; "I plan to exercise vigorously at least 3 times per week for the next 2 weeks," 
definitely no - definitely yes) and were averaged for an intention score $(r=.97, p<.001)$.

Expectations were assessed by 2 items ("How likely is it that you will exercise vigorously at least 3 times per week for the next 2 weeks?" not at all likely-extremely likely; "I expect to exercise vigorously at least 3 times per week for the next 2 weeks," unlikely - likely). Items were averaged to form an expectation scale $(r=.97, p<.001)$. Goal realism was measured in the same manner as the Validation Study and Studies 1 and 2. Attitudes (e.g., "For me, exercising vigorously at least 3 times per week for the next 2 weeks would be," useless - useful, unpleasant - pleasant; 8 items, $a=.67)$, subjective norm (e.g., "People who are important to me would" approve-disapprove "of me exercising vigorously at least 3 times per week for the next 2 weeks"; 4 items, $a=.84$ ), and perceived behavioral control (e.g., "I am confident that I can exercise vigorously at least 3 times per week for the next 2 weeks," extremely unconfidentextremely confident; 6 items, $a=.83$ ) were also assessed.

Past behavior and behavior were each assessed by the same two items that were standardized and then averaged ("I have exercised vigorously at least 3 times per week for the last 2 weeks," definitely no - definitely yes; “Over the last four weeks I have exercised vigorously ___ times per week on average"; $r=.77$ for past behavior and .51 for behavior).

\section{Results and Discussion}

Descriptives and intercorrelations are reported in Table 4, and Table 5 reports the linear regression analyses. Replicating the findings from Study 2, we observed that the intention $\times$ goal realism interaction significantly predicted exercise behavior $(\beta=.17, p<.001)$ even after controlling for TPB variables $(\beta=.15, p<.01)$ and TBP variables and past behavior $(\beta=.10, p<$ $.05)$. Simple slopes (see Figure 3 ) indicated that when goal realism was low $(M-1 S D)$, intentions did not predict behavior $(\mathrm{B}=.06, p=.12$ ). However, intentions were strong predictors of behavior 
at high levels of goal realism $(M+1 S D ; \mathrm{B}=.25, p<.001)$. Thus, goal realism moderated intentionbehavior consistency for both an infrequently performed behavior (cervical cancer screening, Study 2) and a frequently performed behavior (exercise, Study 3). 


\section{STUDY 4: GOAL REALISM AND PERFORMANCE OF MULTIPLE HEALTH BEHAVIORS}

Study 4 assessed the generalizability of the findings observed in Studies 2 and 3. In particular, we tested whether goal realism would moderate the intention-behavior relation for a suite of 15 health behaviors (Conner, McEachan, Taylor, O’Hara, \& Lawton, 2015).

\section{Method}

Participants and Procedure. The University of Leeds IRB approved the study protocol. Participants were recruited using a variety of means (e.g., local newspaper advertisement, local government newsletter, internet advertisement) and received $£ 20$ (approximately $\$ 30$ ) worth of gift vouchers for completing questionnaires at three time-points, each separated by one month. Data from the first two time points of the study are reported here. See Conner et al. (2015, study 2) for further details. After eliminating missing data the final sample consisted of 378 adults (279 women) with a mean age of 38.7 years $(S D=13.0)$. The sample was similar to the UK population in terms of age and education (20\% at degree level or above for England), but less likely to be married and more likely to be female. Across the 15 behaviors there were a total of 4604 person-behavior responses available for analysis.

Measures. Participants completed items measuring the same constructs for each of 15 health-related behaviors. The selected behaviors were based on UK government targets for health (Department of Health, 1999, 2004) and behaviors prevalent in the psychological and public health literature: eat 5 fruit and vegetables per day, wear a helmet when riding a bicycle, take recommended levels of physical activity, exercise regularly, eat a low fat diet, use sunscreen of at least $15 \mathrm{SPF}$ when exposed to the sun, take vitamin supplements, brush teeth twice a day, 
floss teeth daily, binge drinking, drink more than the recommended daily limits of alcohol, smoking, using illegal drugs, exceeding the posted speed limit when driving, drinking and driving. The behaviors specified recommended levels whenever guidelines existed (e.g., eating five fruit and vegetables per day, using sunscreen of at least $15 \mathrm{SPF}$ ).

Items were consistent across behaviors and measured on 7-point scales. Intention was measured by one item that remained consistent across behaviors (e.g., "I intend to exercise regularly over the next four weeks," strongly disagree - strongly agree). Expectation was measured by one item that remained consistent across behaviors (e.g., "I am likely to exercise regularly over the next four weeks," very unlikely - very likely). Goal realism was computed in the same manner as the Validation Study and Studies 1-3. Attitude was measured using four items (e.g., "Exercising regularly over the next four weeks would be," harmful - beneficial, worthless - valuable, unpleasant - pleasant, not enjoyable - enjoyable, mean $\alpha=.86)$.

Subjective norm was measured by two items (e.g., "Most people that are important to me think that" I should - I should not "exercise regularly over the next four weeks"; "I think that most people who are important to me will exercise regularly over the next four weeks," definitely nodefinitely yes; mean $r=.40$ ). Perceived behavioral control (PBC) was measured by two items (e.g., "If it were entirely up to me, I am confident that I could exercise regularly over the next four weeks," strongly disagree - strongly agree; "I have control over whether or not I exercise regularly over the next four weeks," strongly disagree - strongly agree; mean $r=.41)$. All the above questions were recoded such that higher values represented more positive views of positive health behaviors (and more negative views of negative health behaviors).

Behavior and past behavior were measured by the same items at time 1 and 2 ("On how many days in the past four weeks have you performed [behavior]?"). For sunscreen use, which is 
context dependent, the question posed was: "In the past four weeks I have used sunscreen of at least $15 \mathrm{SPF}$ when exposed to the sun," never-always, and was scored on a 1-7 scale. In order to use comparable measures of behavior, all scores were converted to percentage of time behaviors performed, i.e., $0 \%$ is 0 days or never, $100 \%$ is 28 days or always.

Analyses. Data were analyzed in SPSS (version 20, SPSS Inc) and HLM (version 7, SSI). As behavior was clustered within individuals, the data were analyzed using Hierarchical Linear Modeling using HLM7 (Raudenbush \& Bryk, 2002) and random effects were used in order to allow variation across individuals. The data contained a two-level hierarchical structure, Level 1 being the within-person variation and Level 2 being the between-person variability. The Level 1 predictor variables were centered on the group mean. We report unstandardized coefficients, standard errors and standardized coefficients (calculated using the procedure outlined in Hox, 2002).

\section{Results and Discussion}

Table 6 shows the results of the hierarchical linear modeling. Intentions $(\beta=0.621, p<$ $.001)$ and the intentions $\times$ goal realism interaction $(\beta=1.373, p<.001)$ positively and significantly predicted health behavior. The interaction term remained significant controlling for the other TPB variables $(\beta=1.277, p<.001)$ and TPB variables and past behavior $(\beta=1.034, p<.001)$. Simple slopes analyses (Figure 4) using simple slopes analyses using the free software provided by Preacher (Model 1) at http://www.quantpsy.org/interact/hlm2.htm indicated that intentions significantly predict behavior at low levels of goal realism $(\mathrm{B}=4.847, p<.001)$ but were stronger predictors of behavior at high levels of goal realism $(\mathrm{B}=18.517, p<.001)$.

Alternative explanations of Studies 2-4. We ran four additional analyses to rule out potential alternative explanations of the findings. First, we tested whether a difference score 
measure of goal realism offered superior moderation of the intention-behavior relation compared to the measure derived from the Griffin formula. The difference score measure did not moderate intention-behavior consistency in Studies 2-4. Second, we examined whether goal realism is simply an alternative indicator of behavioral expectation, and tested the intention $\times$ expectation interaction term as a predictor of behavior. This interaction never proved significant. Third, we undertook the equivalent analyses for intention and tested the intention $\times$ intention quadratic term. This interaction proved significant in only one out of three tests, and the intention $\times$ goal realism interaction remained significant in this analysis. Thus, even though intention and expectation scores contribute to the measure of goal realism used here, goal realism - but not its components - consistently moderated intention-behavior relations. Finally, even though we controlled for PBC in several analyses, it is possible that goal realism is merely a marker for $\mathrm{PBC}$, and $\mathrm{PBC}$ (rather than goal realism) moderates intention-behavior relations. Evidence did not support this hypothesis, however, as the intention $\times \mathrm{PBC}$ interaction term proved significant in none of the three studies. Thus, the moderating effects of goal realism observed here cannot be attributed to sub-optimal measurement of goal realism or to the influence of expectations, intentions, or PBC/self-efficacy. 


\section{GENERAL DISCUSSION}

We obtained preliminary evidence concerning the convergent validity of our goal realism index using a self-report metric. Four additional studies explored the antecedents and consequences of goal realism. In Study 1, goal importance, fantasy proneness, and pathways thinking were analyzed as predictors of goal realism in relation to 11 health behaviors. We found that goals are most realistic when the goal is important and a person engages in pathways thinking but not in fantasizing. In three subsequent behavioral studies, we examined the influence of goal realism on intention-health behavior relations. Our analyses revealed significant intention $\times$ goal realism interactions such that realistic intentions better predicted behavior than unrealistic intentions in all three studies. This interaction remained significant even when controlling for TPB variables (attitudes, subjective norms, perceived behavioral control) and past behavior. These findings are important in the light of previous research indicating that the gap between intentions and behavior is substantial (e.g., Sheeran \& Webb, 2016). The present research indicates that setting realistic goals may help close the intention-behavior gap and improve the translation of intentions into action. Confidence in this conclusion is enhanced by the fact that moderation was observed (a) in three longitudinal studies with 4- to 26-week follow-ups, (b) among patients, members of the public, and students, (c) using objective and self-report measures of behavior, and (d) across more than 15 different health behaviors.

These are the first studies to operationalize goal realism via an adaptation of Griffin's ambivalence formula (Thompson et al., 1995) that indexes the consistency between people's intentions and expectations for health actions. This approach enables the computation of goal 
realism within persons, obviates the need for an observer (who 'knows' the feasibility of health actions), and avoids the problems with using difference scores. Simple slopes analyses (Figures 2-4) indicated that participants who intended to act (i.e., scored above the midpoint on the intention scale) particularly benefited from greater goal realism. In other words, the interactions showed that health behavior performance was greatest for those who held high but realistic intentions.

Although the findings obtained here appear robust as they involve multiple samples and behaviors, the studies have limitations that should be acknowledged. First, the present research did not experimentally manipulate goal realism. As these studies are the first to assess goal realism in terms of the alignment of intentions and expectations, correlational tests were a necessary initial step. However, we acknowledge that experimental tests should follow (e.g., using mindset manipulations, Taylor \& Gollwitzer, 1995). Another limitation is that an objective measure of behavior was utilized only in Study 2. However, Studies 3 and 4 replicated the results of Study 2 using self-report measures of behavior (which was the only feasible way to measure the 15 behaviors in Study 4). Additionally, the longest follow-up in the present research was 26 weeks. Further tests over more extended periods are needed to assess the durability of the influence of goal realism on intention-health behavior relations. Finally, the present studies leave several questions unanswered. For instance, although the Validation Study indicated that goal realism was related to anticipated disappointment, it would be valuable to test whether this association holds in relation to experienced disappointment or other affective outcomes in the wake of health behavior (non)performance. Similarly, it would be valuable to explore how goal realism relates to behavioral willingness (Gibbons, Gerrard, Blanton, \& Russell, 1998), self-regulatory processes (de Bruin et al., 2012), and other antecedents of behavior. Additionally, as the validation of our goal realism index 
remains preliminary, replication of our findings with alternate goal realism measures is warranted, as are manipulations of goal realism.

Notwithstanding these limitations, the studies presented here have important implications for interventions as they suggest that setting more realistic intentions should lead to greater health behavior change. But how can goal setting become more realistic? Study 1 indicates that it may be possible to improve goal realism by increasing goal importance and pathways thinking and by decreasing fantasizing. Future research could focus on increasing goal realism through interventions targeting these predictors. Specifically, new studies could test interventions to help people view their goals as important. Davis and Haws (2017) recently demonstrated that it is possible to increase the importance of health goals using both choice sets and persuasion. For instance, considering health in a choice set involving less pressing goals served to increase the importance that participants assigned to health goals. Similarly, a persuasive communication that emphasized the benefits of good health increased goal importance scores.

In the present research, fantasizing predicted lower goal realism which is consistent with fantasy realization theory's proposal that fantasizing about desired outcomes has negative consequences for behavior change (review by Oettingen, 2012). Similarly, thinking about the obstacles in one's present (negative) reality does not, on its own, change behavior. However, when people (a) mentally envisage the desired outcomes of behavior, and then (b) contemplate the obstacles in one's present reality that stand in the way of the behavior, this sequence is termed mental contrasting and leads to increased motivation and action (Johannessen, Oettingen, \& Mayer, 2012; Oettingen \& Gollwitzer, 2009; Sheeran, Harris, Vaughan, Oettingen, \& Gollwitzer, 2013). Mental contrasting also increases people's inclination to plan (Oettingen, Pak, \& Schnetter, 2001) and can be combined with implementation intentions to promote behavior change. Implementation 
intentions are if-then plans that people can form to help them seize opportunities for, or overcome obstacles to goal striving - or in other words, to find pathways to achieving their goals (Gollwitzer $\&$ Sheeran, 2006). Mental contrasting with implementation intentions has proven effective in promoting health behaviors such as diet, physical activity, and weight loss (e.g., Christiansen, Oettingen, Dahme, \& Klinger, 2010; Marquardt, Oettingen, Gollwitzer, Sheeran, \& Liepert, 2017; Stadler, Oettingen, \& Gollwitzer, 2010). Thus, mental contrasting with implementation intentions could be an especially effective intervention for promoting goal realism as this self-regulation tool both (a) offsets the negative effects of fantasizing, and (b) promotes effective pathways thinking.

In conclusion, the present research offers a new conceptual and empirical analysis that could enable researchers to designate particular intentions as more versus less realistic. Goal realism was defined as the alignment of the person's intentions to act and their expectations of action, and evidence was found for the validity of this novel measure. Findings showed that goal importance, fantasy proneness, and pathways thinking combined synergistically to predict goal realism. In three empirical studies, we also observed moderation of the intention-behavior relation by goal realism; realistic intentions were better translated into action compared to unrealistic intentions. The present studies suggest that goal realism offers new insights into the intention-behavior gap and offers directions for behavior change intervention that can and should be tested in future research. 
Table 1. Descriptives and Intercorrelations for Variables in Study $1(N=246)$

\begin{tabular}{lccccc}
\hline & 1 & 2 & 3 & 4 & 5 \\
\hline 1. Pathways thinking & - & $.229^{* * *}$ & $.140^{*}$ & $.323^{* * *}$ & $.338^{* * *}$ \\
2. Goal importance & & - & .115 & $.586^{* * *}$ & $.597^{* * *}$ \\
3. Fantasy proneness & & & - & .050 & .023 \\
4. Intention & & & & - & $.889^{* * *}$ \\
5. Goal realism & & & & & - \\
Mean & 5.92 & 5.38 & 3.14 & 4.78 & 4.06 \\
$(S D)$ & $(1.20)$ & $(0.99)$ & $(2.43)$ & $(1.06)$ & $(1.25)$ \\
\hline
\end{tabular}


Table 2. Descriptives and Intercorrelations for Variables in Study $2(N=854)$

\begin{tabular}{|c|c|c|c|c|c|c|c|}
\hline & 1 & 2 & 3 & 4 & 5 & 6 & 7 \\
\hline 1. Behavior & - & $.291 * * *$ & $.213 * * *$ & $.116^{* * *}$ & $.217 * * *$ & $.123 * * *$ & $.233 * * *$ \\
\hline 2. Intention & & - & $.714^{* * *}$ & $.437 * * *$ & $.691 * * *$ & $.120 * *$ & $.635^{* * *}$ \\
\hline 3. Attitude & & & - & $.647 * * *$ & $.573 * * *$ & $.114 * * *$ & $.474 * * *$ \\
\hline 4. Subjective norm & & & & - & $.505 * * *$ & $.072 *$ & $.304 * * *$ \\
\hline 5. $\mathrm{PBC}$ & & & & & - & $.144 * * *$ & $.448^{* * *}$ \\
\hline 6. Past behavior & & & & & & - & $.124 * * *$ \\
\hline 7. Goal realism & & & & & & & - \\
\hline Mean & 0.74 & 6.59 & 6.74 & 6.82 & 6.65 & 0.91 & 6.27 \\
\hline$(S D)$ & $(0.44)$ & $(1.03)$ & $(0.72)$ & $(0.57)$ & $(0.76)$ & $(0.28)$ & $(1.68)$ \\
\hline
\end{tabular}

Note. $\mathrm{PBC}=$ perceived behavioral control.

$* p<.05 ; * * p<.01 ; * * * p<.001$. 
Table 3. Logistic Regression of Behavior on Intention, Goal Realism, TPB Variables and Past Behavior in Study $2(N=854)$

\begin{tabular}{|c|c|c|c|c|c|}
\hline & Nagelkerke $\mathrm{R}^{2}$ & B & SE & OR & $95 \% \mathrm{CI}$ \\
\hline $\begin{array}{l}\text { Step } 1 \\
\text { Intention }\end{array}$ & $.106^{* * *}$ & .592 & .083 & $1.807 * * *$ & $1.537-2.126$ \\
\hline $\begin{array}{l}\text { Step } 2 \\
\text { Intention } \\
\text { Goal realism } \\
\text { Intention } \times \text { goal realism }\end{array}$ & $.120 * * *$ & $\begin{array}{l}.824 \\
.073 \\
.098\end{array}$ & $\begin{array}{l}.175 \\
.057 \\
.040\end{array}$ & $\begin{array}{l}2.280 * * * \\
1.075 \\
1.103 *\end{array}$ & $\begin{array}{l}1.618-3.214 \\
0.963-1.201 \\
1.018-1.194\end{array}$ \\
\hline $\begin{array}{l}\text { Step } 3 \\
\text { Intention } \\
\text { Goal realism } \\
\text { Intention } \times \text { goal realism } \\
\text { Attitude } \\
\text { Subjective norm } \\
\text { Perceived behavioral control }\end{array}$ & $.123 * * *$ & $\begin{array}{l}.799 \\
.071 \\
.107 \\
.133 \\
-.247 \\
.103\end{array}$ & $\begin{array}{l}.204 \\
.057 \\
.042 \\
.179 \\
.199 \\
.147\end{array}$ & $\begin{array}{l}2.224 * * * \\
1.073 \\
1.113^{*} \\
1.143 \\
0.781 \\
1.109\end{array}$ & $\begin{array}{l}1.491-3.318 \\
0.961-1.199 \\
1.025-1.207 \\
0.805-1.622 \\
0.528-1.154 \\
0.831-1.478\end{array}$ \\
\hline $\begin{array}{l}\text { Step } 4 \\
\text { Intention } \\
\text { Goal realism } \\
\text { Intention } \times \text { goal realism } \\
\text { Attitude } \\
\text { Subjective norm } \\
\text { Perceived behavioral control } \\
\text { Past behavior }\end{array}$ & $.132 * * *$ & $\begin{array}{r}.816 \\
.062 \\
.108 \\
.123 \\
-.245 \\
.076 \\
.664\end{array}$ & $\begin{array}{l}.206 \\
.057 \\
.042 \\
.180 \\
.202 \\
.147 \\
.268\end{array}$ & $\begin{array}{l}2.262^{* * *} \\
1.064 \\
1.115^{* *} \\
1.131 \\
0.783 \\
1.079 \\
1.943^{*}\end{array}$ & $\begin{array}{l}1.510-3.390 \\
0.951-1.190 \\
1.027-1.210 \\
0.794-1.610 \\
0.527-1.162 \\
0.808-1.440 \\
1.148-3.288\end{array}$ \\
\hline
\end{tabular}

Note. OR $=$ Odds Ratio

$* p<.05, * * p<.01, * * * p<.001$. 
Table 4. Descriptives and Intercorrelations for Variables in Study $3(N=237)$

\begin{tabular}{|c|c|c|c|c|c|c|c|}
\hline & 1 & 2 & 3 & 4 & 5 & 6 & 7 \\
\hline 1. Behavior & - & $.724 * * *$ & $.532 *$ & $.259 * * *$ & $.582 * * *$ & $.796^{* * *}$ & $.779 * * *$ \\
\hline 2. Intention & & - & $.715^{*}$ & $.331 * * *$ & $.569 * * *$ & $.734 * * *$ & $.875^{* * *}$ \\
\hline 3. Attitude & & & - & $.388 * * *$ & $.428 * * *$ & $.544 * *$ & $.673 * *$ \\
\hline 4. Subjective norm & & & & - & $.329 * * *$ & $.276^{* * *}$ & $.289 * * *$ \\
\hline 5. $\mathrm{PBC}$ & & & & & - & $.623 * * *$ & $.674 * * *$ \\
\hline 6. Past behavior & & & & & & - & $.789 * * *$ \\
\hline 7. Goal realism & & & & & & & - \\
\hline Mean & -0.10 & 4.51 & 5.30 & 5.74 & 5.18 & 0.00 & 3.77 \\
\hline (SD) & $(0.90)$ & $(2.14)$ & $(1.28)$ & $(1.09)$ & $(1.31)$ & $(0.94)$ & $(2.44)$ \\
\hline
\end{tabular}

Note. $\mathrm{PBC}=$ perceived behavioral control.

$* p<.05 ; * * p<.01 ; * * * p<.001$. 
Table 5. Linear Regressions of Behavior onto Intention, Goal Realism, Intention $\mathrm{x}$ Realism, TPB Variables and Past Behavior in Study 3 $(N=237)$

\begin{tabular}{|c|c|c|c|c|c|}
\hline & $R^{2}$ & $\Delta R^{2}$ & $\mathrm{~B}$ & $S E$ & $\beta$ \\
\hline \multicolumn{6}{|l|}{ Step 1} \\
\hline Intention & .524 & $.524 * * *$ & .304 & .019 & $.724 * * *$ \\
\hline \multicolumn{6}{|l|}{ Step 2} \\
\hline Intention & .634 & $.110 * * *$ & .151 & .040 & $.360 * * *$ \\
\hline Goal realism & & & .167 & .035 & $.454 * * *$ \\
\hline Intention $\times$ goal realism & & & .040 & .011 & $.167 * * *$ \\
\hline \multicolumn{6}{|l|}{ Step 3} \\
\hline Intention & .637 & .003 & .150 & .042 & $.356 * * *$ \\
\hline Goal realism & & & .155 & .037 & $.422 * * *$ \\
\hline Intention $\times$ goal realism & & & .036 & .011 & $.152 * *$ \\
\hline Attitude & & & -.012 & .042 & -.018 \\
\hline Subjective norm & & & .008 & .036 & .010 \\
\hline Perceived behavioral control & & & .047 & .039 & .068 \\
\hline \multicolumn{6}{|l|}{ Step 4} \\
\hline Intention & .703 & $.066 * * *$ & .090 & .039 & $.213 *$ \\
\hline Goal realism & & & .089 & .035 & $.242 *$ \\
\hline Intention $\times$ goal realism & & & .024 & .010 & $.100 *$ \\
\hline Attitude & & & -.009 & .038 & -.013 \\
\hline Subjective norm & & & .003 & .033 & .004 \\
\hline Perceived behavioral control & & & .005 & .036 & .007 \\
\hline Past behavior & & & .419 & .059 & $.440 * * *$ \\
\hline
\end{tabular}

Note. $* p<.05 ; * * p<.01 ; * * * p<.001$. 
Table 6. Hierarchical Multi-Level Regressions Predicting Behavior for Study 4 ( $N$ of participants $=378 ; N$ of observations $=4604$ )

Predictors

\section{Step 1}

Intercept $\left(\gamma_{00}\right)$

Intentions $\left(\gamma_{10}\right)$

\section{Step 2}

Intercept $\left(\gamma_{00}\right)$

Intentions $\left(\gamma_{10}\right)$

Goal realism $\left(\gamma_{20}\right)$

Intentions $\times$ goal realism $\left(\gamma_{30}\right)$

\section{Step 3}

Intercept $\left(\gamma_{00}\right)$

Intentions $\left(\gamma_{10}\right)$

Goal realism $\left(\gamma_{20}\right)$

Intentions $\times$ goal realism $\left(\gamma_{30}\right)$

Attitudes $\left(\gamma_{40}\right)$

Subjective norm $\left(\gamma_{50}\right)$

Perceived behavioral control $\left(\gamma_{60}\right)$

\section{Step 4}

Intercept $\left(\gamma_{00}\right)$

Intentions $\left(\gamma_{10}\right)$

Goal realism $\left(\gamma_{20}\right)$

Intentions $\times$ goal realism $\left(\gamma_{30}\right)$

Attitudes $\left(\gamma_{40}\right)$

Subjective norm $\left(\gamma_{50}\right)$

Perceived behavioral control $\left(\gamma_{60}\right)$

Past behavior $\left(\gamma_{70}\right)$
42.720

8.070

42.732

11.381

$-0.515$

2.317

42.678

10.989

0.910

2.155

$-3.270$

9.862

$-9.179$

42.696

6.169

$-0.364$

1.746

$-4.210$

8.375

$-9.963$

7.076
B $S E \quad \beta$

B $\quad S E \quad \beta$

Note. $\mathrm{B}=$ unstandardized coefficient. Intercept only model at Step 0, Deviance $=47094.9$; Step 1, Deviance $=46138.1, X^{2}(2)=956.8, p<.001$; Step 2, Deviance $=45730.7, X^{2}(7)=$ $407.4, p<.001$; Step 3, Deviance $=44031.3, X^{2}(18)=1699.4, p<.001$; Step 4, Deviance $=$ $43573.5, X^{2}(8)=457.8, p<.001$.

$* p<.05 ; * * p<.01 ; * * * p<.001$. 


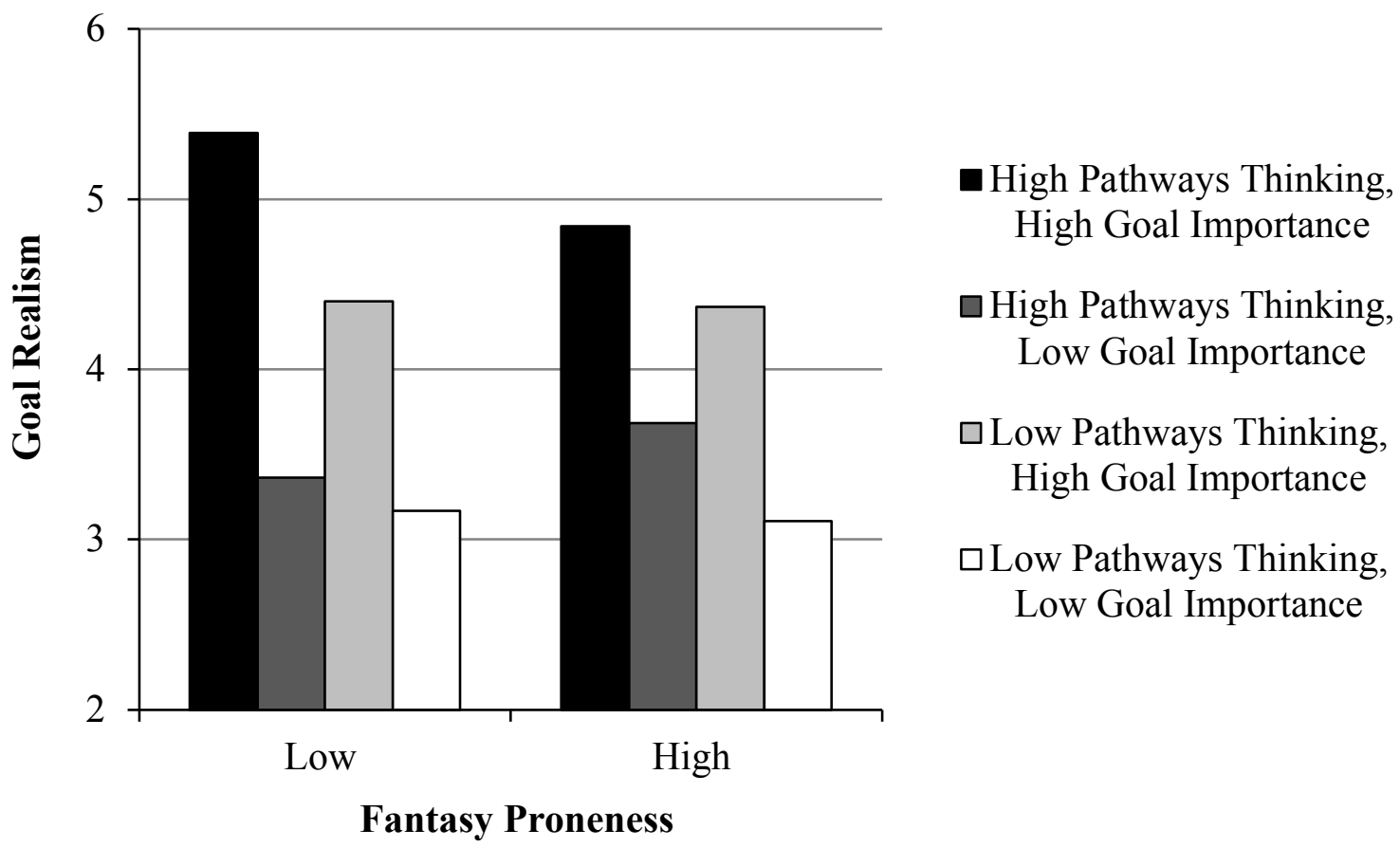

Figure 1. Three-Way Interaction between Fantasy Proneness, Pathways Thinking, and Goal Importance Predicting Goal Realism in Study $1(N=246)$. 


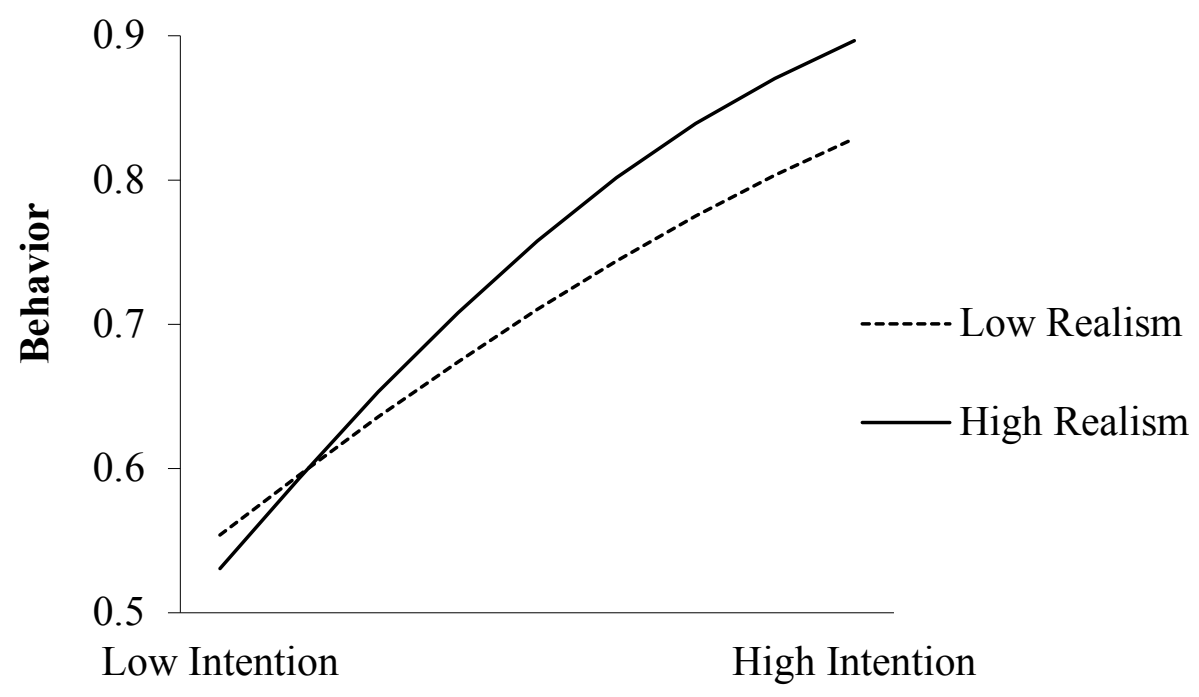

Figure 2. Interaction between Intention and Goal Realism Predicting Cervical Cancer Screening in Study $2(N=854)$. 


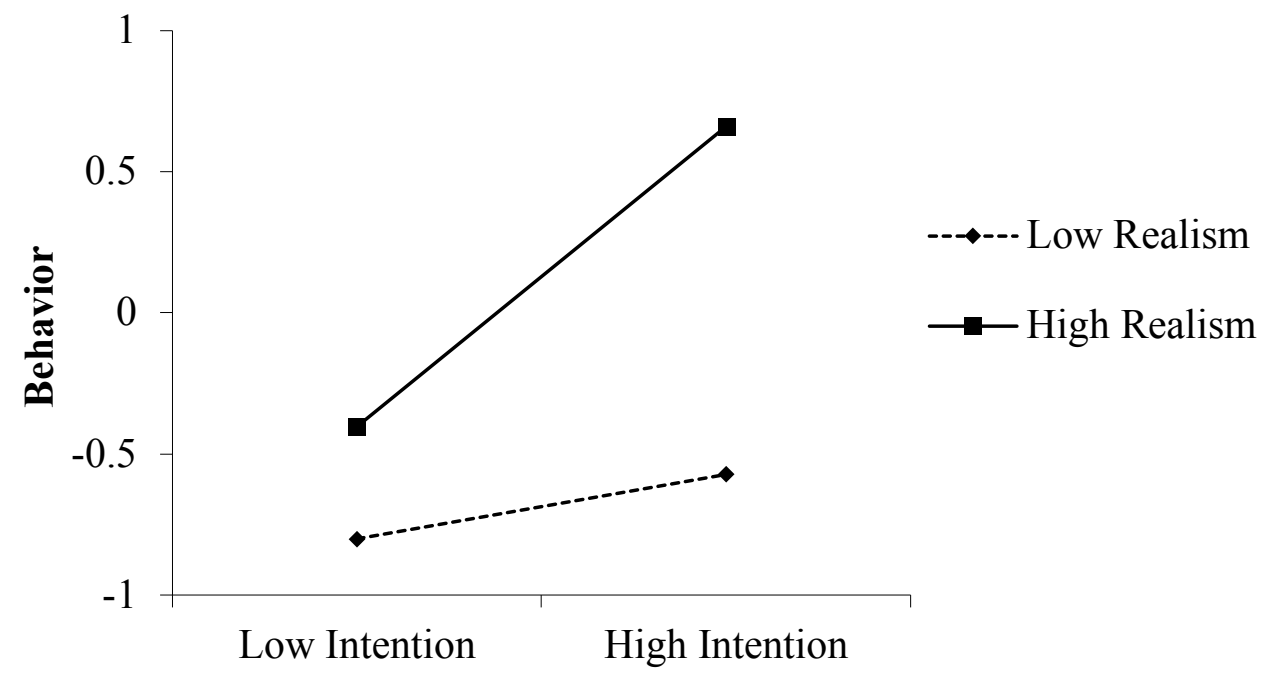

Figure 3. Interaction between Intention and Goal Realism Predicting Physical Activity in Study $3(N=237)$. 


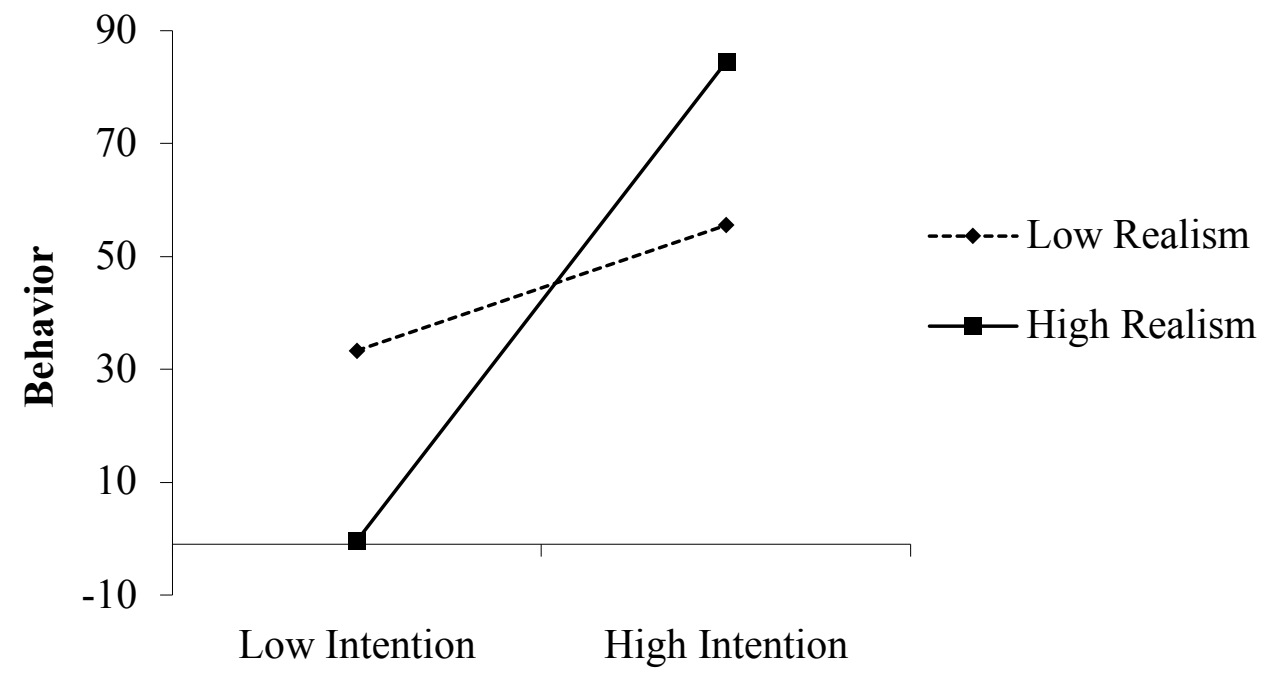

Figure 4. Interaction between Intention and Goal Realism in Predicting 15 Health Behaviors in Study 4 ( $N$ of participants $=378 ; N$ of observations $=4604)$. 


\section{REFERENCES}

Armitage CJ, Norman P, Alganem S, Conner M. Expectations are more predictive of behavior than behavioral intentions: Evidence from two prospective studies. Ann Behav Med. 2015;49(2):239-246.

Austin JT, Vancouver JB. Goal constructs in psychology: Structure, process, and content. Psychol Bull. 1996;120(3):338-375.

Bassili JN. Meta-judgmental versus operative indexes of psychological attributes: The case of measures of attitude strength. J Pers Soc Psychol. 1996;71(4):637.

Breckler, S. J. (1994). A comparison of numerical indexes for measuring attitude ambivalence. Educ Psychol Meas, 54(2), 350-365.

Buehler R, Griffin D, Ross M. Exploring the "planning fallacy": Why people underestimate their task completion times. J Pers Soc Psychol. 1994;67(3):366-381.

Casler K, Bickel L, Hackett E. Separate but equal? A comparison of participants and data gathered via Amazon's MTurk, social media, and face-to-face behavioral testing. Comput Human Behav. 2013;29(6):2156-2160.

Christiansen S, Oettingen G, Dahme B, Klinger R. A short goal-pursuit intervention to improve physical capacity: A randomized clinical trial in chronic back pain patients. Pain. 2010;149(3):444-452.

Conner M, Abraham C, Prestwich A, Hutter R, Hallam J, Sykes-Muskett B, Morris B, Hurling R. Impact of goal priority and goal conflict on the intention-health-behavior relationship: Tests on physical activity and other health behaviors. Health Psychol. 2016;35(9):1017-1026.

Conner M, McEachan R, Taylor N, O'Hara J, Lawton R. Role of affective attitudes and anticipated affective reactions in predicting health behaviors. Health Psychol. 2015;34(6):642-652.

Cunningham E. How can I support my clients in setting realistic weight loss goals? J Acad Nutr Diet. 2014;114(1):176. 
Davis SW, Haws KL. Don't sweat the big stuff: Emphasizing importance hinders goal pursuit for consumers low in dispositional self-control resources. $J$ Assoc Consum Res. 2017;2(1):93-104.

de Bruin M, Sheeran P, Kok G, Hiemstra A, Prins JM, Hospers HJ, van Breukelen GJP. Selfregulatory processes mediate the intention-behavior relation for adherence and exercise behaviors. Health Psychol. 2012;31(6):695-703.

Department of Health. Choosing health: Making healthier choices easier. Department of Health, $\mathrm{UK} ; 2004$.

Department of Health. Saving lives: Our healthier nation. London: UK Stationary Office; 1999.

Doran GT. There's a SMART way to write management's goals and objectives. Manag Rev. 1981;70(11):35-36.

Fishbein M, Triandis H, Kanfer F, Becker M, Middlestadt S, Eichler A. Factors influencing behavior and behavior change. In: Baum A, Revenson T, Singer JE, eds. Handbook of health psychology. Mahwah, NJ: Lawrence Erlbaum; 2001:3-17.

Gelinas BL, Delparte CA, Hart R, Wright KD. Unrealistic weight loss goals and expectations among bariatric surgery candidates: The impact on pre-and postsurgical weight outcomes. Bariatr Surg Pract Patient Care. 2013;8(1):12-7.

Gibbons FX, Gerrard M, Blanton H, Russell DW. Reasoned action and social reaction: Willingness and intention as independent predictors of health risk. J Pers Soc Psychol. 1998;74(5):1164.

Gollwitzer PM, Moskowitz GB. Goal effects on action and cognition. In: Higgins E, Kruglanski AW, eds. Social psychology: Handbook of basic principles. New York, NY: Guilford Press; 1996:361-399.

Gollwitzer PM, Sheeran P. Implementation intentions and goal achievement: A meta-analysis of effects and processes. Adv Exp Soc Psychol. 2006;38:69-119.

Griffin D, Murray S, Gonzalez R. Difference score correlations in relationship research: A conceptual primer. Pers Relatsh. 1999;6(4):505-518. 
Hauser DJ, Schwarz N. Attentive Turkers: MTurk participants perform better on online attention checks than do subject pool participants. Behav Res Methods. 2016;48(1):400-407.

Hox J. Multilevel analysis: Techniques and applications. Mahwah, NJ: Erlbaum; 2002.

Johannessen KB, Oettingen G, Mayer D. Mental contrasting of a dieting wish improves selfreported health behaviour. Psychol Health. 2012;27(sup2):43-58.

Marquardt MK, Oettingen G, Gollwitzer PM, Sheeran P, Liepert J. Mental contrasting with implementation intentions (MCII) improves physical activity and weight loss among stroke survivors over one year. Rehabil Psychol. 2017;62(4):580-590.

McEachan RR, Conner M, Taylor NJ, Lawton RJ. Prospective prediction of health-related behaviours with the theory of planned behaviour: A meta-analysis. Health Psychol Rev. 2011;5(2):97-144.

Merckelbach H, Horselenberg R, Muris P. The Creative Experiences Questionnaire (CEQ): A brief self-report measure of fantasy proneness. Pers Individ Dif. 2001;31(6):987-995.

Oettingen G, Gollwitzer PM. Making goal pursuit effective: Expectancy-dependent goal setting and planned goal striving. In: Forgas JP, Baumeister R, Tice DM, eds. The psychology of self- regulation: Cognitive, affective, and motivational processes. Philadelphia, PA: Psychology Press; 2009:127-146.

Oettingen G, Pak HJ, Schnetter K. Self-regulation of goal-setting: Turning free fantasies about the future into binding goals. J Pers Soc Psychol. 2001;80(5):736-753.

Oettingen G. Future thought and behaviour change. Eur Rev Soc Psychol. 2012;23(1):1-63.

Raudenbush SW, Bryk AS. Hierarchical linear models: Applications and data analysis methods. New York, NY: Sage; 2002.

Rhodes RE, Bruijn GJ. How big is the physical activity intention-behaviour gap? A metaanalysis using the action control framework. Br J Health Psychol. 2013;18(2):296-309.

Rhodes RE, Dickau L. Moderators of the intention-behaviour relationship in the physical activity domain: A systematic review. Br J Sports Med. 2012;47(4):215-225 
Sheeran P, Harris P, Vaughan J, Oettingen G, Gollwitzer PM. Gone exercising: Mental contrasting promotes physical activity among overweight, middle-aged, low-SES fishermen. Health Psychol. 2013;32(7):802-809.

Sheeran P, Webb TL. From goals to action. In: Aarts H, Elliot AJ, eds. Goal-directed behavior. New York: Guilford; 2012:175-202.

Sheeran P, Webb TL. The intention-behavior gap. Soc Personal Psychol Compass. 2016;10(9):503-518

Sheeran P. Intention - behavior relations: A conceptual and empirical review. Eur Rev Soc Psychol. 2002;12(1):1-36.

Sheppard BH, Hartwick J, Warshaw PR. The theory of reasoned action: A meta-analysis of past research with recommendations for modifications and future research. $J$ Consum Res. $1988 ; 15(3): 325-343$.

Sideridis GD, Kaissidis-Rodafinos A. Goal importance within planned behaviour theory as 'the' predictor of study behaviour in college. Br J Educ Psychol. 2001;71(4):595-618.

Snyder CR, Harris C, Anderson JR, Holleran SA, Irving LM, Sigmon ST, Yoshinobu L, Gibb J, Langelle C, Harney P. The will and the ways: Development and validation of an individual-differences measure of hope. J Pers Soc Psychol. 1991;60(4):570-585.

Snyder CR. Hope theory: Rainbows in the mind. Psychol Inq. 2002;13(4):249-275.

Stadler G, Oettingen G, Gollwitzer PM. Intervention effects of information and self-regulation on eating fruits and vegetables over two years. Health Psychol. 2010;29(3):274-283.

Taylor SE, Gollwitzer PM. Effects of mindset on positive illusions. J Pers Soc Psychol. 1995;69(2):213.

Thompson MM, Zanna MP, Griffin DW. Let's not be indifferent about (attitudinal) ambivalence. In: Petty RE, Krosnick JA, eds. Attitude strength: Antecedents and consequences. Mahwah, NJ: Lawrence Erlbaum; 1995:361-386.

Zhang Y, Fishbach A. Counteracting obstacles with optimistic predictions. J Exp Psychol Gen. 2010;139(1):16-31. 